\title{
Pseudostratified Columnar Ciliated Epithelium
}

National Cancer Institute

\section{Source}

National Cancer Institute. Pseudostratified Columnar Ciliated Epithelium. NCI Thesaurus.

Code C13181.

Epithelium composed of a single layer of cells, appearing as layered because the columnshaped cells vary in height so the nuclei are at different levels. The basal portions of all the cells are in contact with the basement membrane. It lines the respiratory system and the male reproductive tract. The cilia in the respiratory tract are motile, while the stereocilia in the male reproductive tract are immobile. 